\title{
DIREÇÃO DE ESTABELECIMENTO DE ENSINO PÚBLICO - ELEIÇÃO - INCONSTITUCIONALIDADE
}

1. O Plenário do Supremo Tribunal Federal, em várias oportunidades, tem declarado a inconstitucionalidade de leis estaduais que tratam de eleições para os cargos de direção dos estabelecimentos de ensino público.

2. Precedentes (Rp 1.473-SC; ADI 5I-RJ; ADI 490-AM; ADI 123-SC; ADI 640-MG; e mais recentemente, na ADI 578-RS).

3. No caso, dispōe o inciso VII do art. 178 da Constituição do Estado do Paraná:

"Art. 178. O ensino será ministrado com base nos seguintes princípios: ..

VII - gestão democrática e colegiada das instituiçōes de ensino pelo poder público estadual, adotando se o sistema eletivo, direto e secreto, na escolha dos dirigentes, na forma da lei."

4. Pelas mesmas razões deduzidas nos precedentes referidos, são inconstitucionais, no texto do inciso VII do art. 178 da Constituição do Estado do Paraná, as expressões "adotando-se o sistema eletivo. direto e secreto. na escolha dos dirigentes, na forma da lei".

5. No mais, o inciso VII não é de ser declarado inconstitucional, ou seja, no ponto em que estabelece, como princípio do ensino, no Paraná, a "gestão democrática e colegiada".

6. Ação Direta julgada procedente, em parte, para declaração de inconstitucionalidade. com eficácia "ex tunc", das expressões "adotando-se o sistema eletivo, direto e secreto, na escolha dos dirigentes, na forma da lei" contidas no inciso VII do art. 178 da Constituição do Estado do Paraná. 


\title{
SUPREMO TRIBUNAL FEDERAL
}

Ação Direta de Inconstitucionalidade $n^{\Perp} 606$

\author{
Requerente: Governador do Estado do Paraná \\ Requerido: Assembléia Legislativa do Estado do Paraná \\ Relator: Sr. Ministro SYDNEY SANCHES
}

\begin{abstract}
ACORDÃO
Vistos, relatados e discutidos estes autos, acordam os Ministros do Supremo Tribunal Federal, em Sessão Plenária, na conformidade da ata de julgamento e das notas taquigráficas, por votação majoritária, julgar procedente, em parte, a ação direta e declarar a inconstitucionalidade da expressão "adotando-se o sistema eletivo, direto e secreto, na escolha dos dirigentes, na forma da lei", contida no inciso VII do art. 178 da Constituição do Estado do Paraná, vencidos os Ministros MARCO AURÉLIO e SEPÚLVEDA PERTENCE. Votou o Presidente. Ausentes, justificadamente, os Ministros CELSO DE MELLO (Presidente) e CARLOS VELLOSO, e, neste julgamento, o Ministro MAURÍCIO CORRÊA. Presidiu o julgamento, o Ministro MOREIRA ALVES.

Brasília, 25 de março de 1999.

MOREIRA ALVES - PRESIDENTE

SYDNEY SANCHES - RELATOR
\end{abstract}

\section{RELATÓRIO}

\section{O SENHOR MINISTRO SYDNEY SAN-} CHES - (Relator):

A ilustre Subprocuradora-Geral da República Dr' ANADYR DE MENDONÇA RODRIGUES, no parecer de fls. $166 / 172$, aprovado pelo Exmo. Sr. Procurador-Geral, Dr. GERALDO BRINDEIRO, resumiu a inicial, as informações $c$ os demais elementos do processo e, em seguida, opinou, nos termos seguintes:

"EMENTA - Provimento de cargos em comissāo mediante procedimento eletivo:
"Sendo o cargo em comissāo conformado à confiança do Poder nomeante, não se conciliam a livre nomeação com a escolha por eleição. A Constituição limita o provimento dos cargos públicos às formas previstas no artigo 97, parágrafos $1^{0}$ e $2^{\circ}$, não deixando margem a que seja criado processo eletivo para os cargos em comissão. Não tendo as escolas públicas de primeiro grau a autonomia administrativa e financeira conferida à Universidade, não há que cogitar da investidura em seus cargos de direção por eleição." (1.473-SC), ADIN 244-9-RJ, ADIN 387-9RO, ADIN 573-1-SC, ADIN 578-2-RS, ADIN 640-1-MG e ADIN 640-1-MG. Ação Direta de Inconstitucionalidade suscetível de ser julgada procedente.

1. O GOVERNADOR DO ESTADO DO PARANÁ propôs, em 16 de outubro de 1991, Ação Direta de Inconstitucionalidade, tendo como objeto o art. 178, VII, da Constituição daquele Estado e a Lei estadual $n^{2} 7.961$, de 21 de novembro de 1984.

2. A disposição da Carta Estadual tida como inconstitucional é do seguinte teor:

“Art. 178. O ensino será ministrado com base nos seguintes princípios:

VII - gestão democrática e colegiada das instituiçōes de ensino pelo poder público estadual, adotando-se o sistema eletivo, direto e secreto, na escolha dos dirigentes, na forma da lei,"

3. Alega o Requerente o que se segue:

"A inconstitucionalidade das normas estaduais se apresenta na violação dos princípios de organização impostos aos Estados no art. 25 da Constituição da República. Entre os princípios violados no inciso VII do art. 178 
da Constituição è na Lei n² 7.961/84 está inicialmente aquele que assegura autonomia c independência do Poder Executivo - art. ${ }^{2}$ da Constituição da República - , do qual decorrem em enquadramento de sistema, os que conferem ao chefe do Executivo a competência da direçāo superior da Administração Pública. (art. 84. II, da Constituiçāo Federal) e seu corolário, o poder discricionário de nomeaçāo e designaçāo para cargos em comissão e funções de confiança (art. 37, II, da Constituição da União)." (fls. 5)

4. Essa Excelsa Corte houve por bem negar conhecimento à Ação, no tocante à Lei estadual $n^{2} 7.961$, de 1984. e, no tocante ao art. 178, VII, da Constituição do Estado do Paraná, deferiu medida cautelar, por meio do $\mathrm{V}$. aresto de f7s. $82 / 135$, que exibe a seguinte ementa:

"Sistema eletivo direto, para a escolha de dirigentes das instituif̧ões de ensino público estadual. Relevância do fundamento juridico da impugnação desse critério, perante os artigos 37, II e 84, VI, da Carta Federal. Precedente: ADin 578-RS (medida cautelar).

Cautelar deferida para suspensão dos efeitos do inciso VII do art. 178 da Constituição do Paraná. Nāo se conhecendo da ação quan. to à Lei estadual n" 7.961, de 21-11-84, por ser anterior à Carta Federal de 1988, em que se funda a argiiiçaio de inconstitucionalidade." (in DJ de 27.3.92)

5. As informações prestadas, em essência, apegam-se ao que reza o art. 206, VI, da Constituiçāo da República, para sustentar a constitucionalidade do art. 162, VI, da Constituição do Estado de Santa Catarina (fls. 138/150). no que foram acompanhadas pela manifestação do Exmo. Sr. Advogado-Geral da União (fls. 158/164).

6. Isto posto, deve dizer-se que se trata de matéria que já recebeu definição, por parte desse Colendo Supremo Tribunal Federal.

7. De fato, ainda sob a precedente ordem constitucional, em 14 de setembro de 1988. ocorreu 0 , julgamento da Representação $n^{9}$ 1.473-SC (Relator. Ministro CARLOS MADEIRA), na qual era argüida a inconstitucionalidade do art. 10 $^{\text {da }}$ Lei estadual $n^{0} 6.709$. de 12 de setembro de 1985. ficando decidido o que está assim resumido na ementa do julgado:

"Representação de Inconstitucionalidade. Nomeação para cargo em comissão de Diretor de escola pública, mediante eleição pelos professores, alunos e pais de alunos. Senda o cargo em comissão conformado à confiança do Poder nomeante, não se conciliam a livre nomeação com a escolha por eleição. A Constituição limita o provimento dos cargos públicos às formas previstas no artigo 97 , parágrafos $1^{2}$ e $2^{2}$, não deixando margem a que seja criado processo eletivo para os cargos em comissão. Não tendo as escolas públicas de primeiro grau a autonomia administrativa e financeira conferida à Universidade, não há que cogitar da investidura em seus cargos de direçāo por eleição. Representação julgada procedente e declarada inconstitucional o artigo 10 da Lei 7.709 , de 12 de setembro de 1985, do Estado de Santa Catarina."

(in DJ de 14.10.88, p. 26.380)

8 . Seguiu-se, pela ordem cronológica, o julgamento liminar da Ação Direta de Inconstitucionalidade $\mathrm{n}^{2} 244-9-\mathrm{RJ}$, ocorrido em 18 de abril de 1990 (Relator, Ministro CELSO DE MELLO), em que era arguiida a inconstitucionalidade do art. $180, \S 4^{\circ}, b$ e $c$, da Constituição do Estado do Rio de Janeiro, havendo sido deferida medida cautelar. mediante V. Acórdão assim ementado:

"Açāo Direta de Inconstitucionalidade Constituiçāo do Estado do Rio de Janeiro Polícia Civil - Co-participação popular nos atos de provimento dos cargos de Delegado de Polícia - Investidura a termo - Restituição funcional por órgão estranho à Chefia do Poder Executivo - Relevo juridico do rema - "Periculum in mora" - Suspensão cautelar deferida.

A subordinação constitucional da Polícia Civil ao Governador do Estado (C.F., art. 144. $\left.\$ 6^{*}\right)$ acentua a integração do organismo policial na esfera da administraçāo pública local, a primazia político-jurídica do Chefe do Poder Executivo dessa unidade da Federą̧āo. Os preceitos ora impugnados, inscritos na Constiturição do Rio de Janeiro, parecem restringir - com ofensa ao princípio da 
separação dos poderes - a competência jurídico-administrativa do Governador do Estado, afetada, em seu exercicio, por um siste. ma de co-participação popular nāo autorizado, prima facie, pelo texto da Lei Fundamental. Ao relevo juridico do tema, associa-se situaf̧ão configuradora do "periculum in mora". a justificar o deferimento do provimento cautelar requerido."

(in DJ de 25.5 .90 , p. 4.603 , RTJ 132/86 e Lex/STF 141/118)

9. Em seqüência, adveio o julgamento liminar da Ação Direta de Inconstitucionalidade $\mathrm{n}^{\mathrm{e}}$ 387-9-RO, ocorrido em $1^{2}$ de março de 1991 (Relator, Ministro CELSO DE MELLO), com argüição de inconstitucionalidade dos artigos $4^{\circ}, \S 2^{\circ}$, e 50 , parágrafo único. da Lei Complementar estadual $n^{2} 36$, de 18 de junho de 1990, havendo sido deferida medida cautelar, mediante V. Acórdão assim ementado, no que interessa a esta Ação:

"Lei Complementar estadual - Diretor de escola pública - Forma eletiva de provimento do cargo".

(in DJ de 11.10 .91 , p. 14.247, RTJ 135/905 e Lex/STF 156/23)

10. A seguir, tem-se o julgamento liminar da Açāo Direta de Inconstitucionalidade 5731-SC, ocorrido em 5 de setembro de 1991 (Relator, Ministro NÉRI DA SILVEIRA). com argüição de inconstitucionalidade da Lei estadual $n^{2} 8.040$, de 26 de julho de 1990 , havendo sido deferida medida cautelar, mediante V. Acórdão assim ementado:

"Ação Direta de Inconstitucionalidade. Lei ne 8.040, de 26/7/1990, do Estado de Santa Catarina, que dispõe sobre as funçōes de direção de escolas públicas, forma de escolha de diretores, por processo eletivo, dando outras providências. Alegações de ofensa aos arts. $61, \S 1$ 1, II, letra “c”, e art. 37, II, ambos da Constituição Federal. Relevância jurídica dos fundamentos da inicial e "periculum in mora" caracterizados. Medida cautelar deferida, para suspender a vigência da Lei $n^{Q}$ 8.040, de 26/7/1990, do Estado de Santa Catarina, até o julgamento final da ação."

(in DJ de 27.11.92)
11. Seguiu-se-lhe o julgamento liminar da Ação Direta de Inconstitucionalidade $n^{2} 578$ 2-RS, ocorrido em 25 de setembro de 1991 (Relator, Ministro PAULO BROSSARD). com argüição de inconstitucionalidade do art. 213, $\$ 12$, da Constituição do Estado do Rio Grande do Sul, dos artigos $1^{2}$ a 29 da Lei estadual $\mathrm{n}^{2}$ 9.233, de 13 de fevereiro de 1991 , e da Lei estadual n 9.263, de 5 de junho de 1991, havendo sido deferida medida cautelar. mediante V. Acórdão assim ementado:

"Constitucional. O Governador é o Chefe da Administração estadual. $\mathrm{O}$ art. $213, \S 1^{\circ}$ da Constituição do RGS e as leis que o complementam, estabelecendo que a escolha dos diretores e vice-diretores das escolas públiciı estaduais seja feita mediante eleição, pela denominada comunidade escolar, com exclusāo do Governador do Estado, ofenderiam, "prima facie", a prerrogativa do Chefe da administração estadual - CF, art. 37, II, 84, XXV.

Precedentes do STF: Rep. 1473, ADin 244, 387 e 573 . A hierarquia é essencial à organização administrativa. Princípios a que está sujeita.

Relevância do fundamento jurídico. "Periculum in mora" ocorrente na espécie. Cautelar concedida."

(in DJ de 2.4.93)

12. Por fim, foi a vez, então, do julgamento liminar da Ação Direta de Inconstitucionalidade n640-1-MG, ocorrido em 22 de novembro de 1991 (Relator, Ministro MARCO AURÉLIO), com arguiição de inconstitucionalidade do art. 196, VIII, da Constituiçāo do Estado de Minas Gerais, havendo sido deferida medida cautelar, mediante V. Acórdão assim ementado:

"ESCOLAS - DIRETORES - PROCESSO DE ESCOLHA AÇĀO DIRETA DE INCONSTITUCIONALIDADE - CAUTELAR. Concorrem os pressupostos indispensáveis à concessāo da cautelar quando os atos normativos impugnados prevêem a escolha dos diretores das escolas públicas mediante processo seletivo peculiar e para o cumprimento de mandato. Ao primeiro exame, a hipótese envolve cargos a serem preenchidos à 
livre discrição. sendo impróprio o afastamento, por norma legal, da atuação do Executivo."

\section{(in DJ de 13.3.92)}

13. Tudo posto, quer parecer manifesto que esta Açāo Direta de Inconstitucionalidade é procedente. também de meritis.

14. De fato, segundo deixou assentado essa Suprema Corte no pioneiro julgamento da Representação $n^{2} 1.473-S C$ :

"Sendo o cargo em comissāo conformado a confiança do Poder nomeante, não se conciliam a livre nomeação com a escolha por eleição. A Constituição limita o provimento dos cargos públicos às formas previstas no artigo 97 , parágrafos $1^{2}$ e $2^{\circ}$, não deixando margem a que seja criado processo eletivo para os cargos em comissāo. Não tendo as escolas públicas de primeiro grau a autonomia administrativa e financeira conferida à Universidade, não há que cogitar da investidura em seus cargos de direção por eleição."

15. Em verdade, o texto estadual impugnado pretendeu estar apoiado na Constituição da República. no que a Carta Federal assim dispōe:

"Art. 206. O ensino será ministrado com base nos seguintes princípios:

VI - gestāo democrática do ensino público, na forma da lei."

16. Trata-se, entretanto, de entendimento que deixou de levar em consideração:

16.1. de um lado, a circunstância capital de que tal dispositivo da Constituição Federal deve ser aplicado de modo harmônico, frente aos demais comandos constitucionais, e, em especial. com acatamento ao que determina o art. 37. II. da Carta de 1988;

16.2. de outro, o fato de que a "gestão democrática” do ensino público pode ser implementada através de muitas vias, sendo desarrazoado o pensamento de que só se realizaria mediante a instituiçāo de eleições para o provimento dos cargos de direçāo nas escolas públicas.

17. O parecer é, por conseguinte, de que a Ação Direta de Inconstitucionalidade deva ser julgada procedente."

É o Relatório.

\section{VOTO}

O SENHOR MINISTRO SYDNEY SANCHES - (Relator):

1. Ainda sob a égide da Emenda Constitucional $n^{\circ} 1 / 69$, decidiu o Plenário desta Corte, por unanimidade de votos, no julgamento da Representaçāo no 1.473-SC, de que foi Relator o eminente e saudoso Ministro CARLOS MADEIRA, em data de 14.09.1988 (RTJ130/1006):

"Representação de Inconstitucionalidade. Nomeação para cargo em comissão de diretor de escola pública. mediante eleição pelos professores, alunos e pais de alunos. Sendo o cargo em comissão conformado à confiança do poder nomeante, não se conciliam a livre nomeação com a escolha por eleição. A Constituição limita o provimento dos cargos públicos às formas previstas no artigo 97, parágrafos $1^{2}$ e $2^{2}$, nāo deixando margem a que seja criado processo eletivo para os cargos em comissão. Não tendo as escolas públicas de primeiro grau a autonomia administrativa $\mathrm{e}$ financeira conferida à Universidade, não há que cogitar da investidura em seus cargos de direção por eleição.

Representação julgada procedente e declarada inconstitucional o artigo $1^{2}$ da Lei $n^{0}$ 6.709, de 12 de setembro de 1985, do Estado de Santa Catarina."

2. Já sob a vigência da atual Constituição Federal, de 5 de outubro de 1988, o Plenário concluiu no mesmo sentido, desta vez, por maioria de votos, na ADI n 51-RJ, relatado pelo Ministro PAULO BROSSARD, a 25 de outubro de 1989 (RTJ-148/03):

"Universidade Federal. Autonomia (art. 207, CF). Ação Direta de Incontitucionalidade. Resolução n" 2/88 do Conselho Universitário da UFRJ, que dispōe sobre eleição do Reitor e Vice-Reitor. Inconstitucionalidade. Ofensa ao inciso $X e$ "caput" do art. $48 \mathrm{e}$ inciso XXV do art. 84, ambos da Constituição Federal."

3. A 03 de fevereiro de 1997, ainda por maioria, assentou o Plenário, no julgamento da ADI n² 490-5-Amazonas. Relator o Ministro OCTÁVIO GALLOTTI (DJ de 20.06.97, Ementário $\mathrm{n}^{\mathrm{Q}}$ 1.874-01): 
"Inconstitucionalidade, perante a Carta Federal, do art. 199 da Constituição do Amazonas, na parte em que determina a realização de eleiçōes para os cargos de direção dos estabelecimentos de ensino público.

Não se confunde a qualificação de democrática da gestão do ensino público (art. 206. VI, da Constituiçâo) com modalidade de investidura, que, há de coadunar-se com o princípio da livre escolha dos cargos em comissão do Executivo pelo Chefe desse Poder (artigo $37, I I$, in fine $e 84, I I e X X V$, ambos da Constituiçāo da República)."

4. Na mesma data, 03.02.1997, Relator o Ministro CARLOS VELLOSO, decidiu a Corte, por maioria, ao julgar a ADI n 123-0, de Santa Catarina (DJ de 12.09.97, Ementário $\mathrm{n}^{2}$ (.882-01):

"EMENTA: CONSTITUCIONAL. ENSINO PÚBLICO. DIRETORES DE ESCOLAS PÚBLICAS: ELEIÇĀO: INCONSTITUCIONALIDADE. Constituição do Estado de Santa Catarina, inciso VI do art. 162.

I. - É inconstitucional o dispositivo da Constituiçāo de Santa Catarina que estabelece o sistema eletivo mediante voto direto e secreto, para escolha dos dirigentes dos estabelecimentos de ensino. É que os cargos públicos ou sāo providos mediante concurso público, ou, tratando-se de cargo em comissão, mediante livre nomeação e exoneração do Chefe do Poder Executivo, se os cargos estão na órbita deste (C.F., art. 37, II, art. 84, XXV).

II. - Ação direta de inconstitucionalidade julgada procedente."

5. A 05 de fevereiro de 1997 , no mesmo sentido, ADI n 640, de Minas Gerais, Redator do Acórdão Ministro MAURICIO CORRÊA, DJ de 11.04.97, p. 12.177, Ementário vol. 01864-01, p. 90):

"EMENTA: AÇÃO DIRETA DE INCONSTITUCIONALIDADE. PROVIMENTO DOS CARGOS DE DIREÇÃO DE UNIDADES ESTADUAIS DE ENSINO POR ELEIÇĀO: ART. 196, VIII, DA CONSTITUIÇÃO ESTADUAL, LEI № 10.486, de 24.07.91, E DECRETO № 32.855, de 27.08.91, TODOS DO ESTADO DE MINAS GERAIS. INCONSTITUCIONALIDADE:
ART. 37, II, "IN FINE", DA CONSTITUIÇĀO FEDERAL.

1. Cabe ao Poder Executivo fazer as nomeaçōes para os cargos em comissāo de diretor de escola pública (CF, art. $37, \mathrm{II}$, "in fine").

2. É inconstitucional a norma legal que subtraí esta prerrogativa do Executivo, ao determinar a realização de processo eleitoral para o preenchimento destes cargos.

3. Ação Direta julgada procedente para declarar a inconstitucionalidade do art. 196, VIII, da Constituição Estadual, a Lei $\mathrm{n}^{2}$ 10.486/91 e do Decreto ne 32.855/91, todos do Estado de Minas Gerais."

6. E mais recentemente, ou seja, a 03 de março de 1998, Relator Ministro MAURÍCIO CORRÊA, acórdāo por maioria, ainda não publicado, mas no mesmo sentido (ADI $\mathrm{n}^{\mathrm{Q}}$ 578-2), quando o Plenário declarou a inconstitucionalidade do parágrafo $1^{\varrho}$ do art. $213 \mathrm{da}$ Constituição do Estado do Rio Grande do Sul, do teor seguinte:

" $\S 12$ - Os diretores das escolas públicas estaduais serão escolhidos, mediante eleição direta e uninominal, pela comunidade escolar, na forma da lei."

Declarou, também, na oportunidade, a inconstitucionalidade das Leis, que regulamentaram a referida norma da Constituição Estadual.

7. Na presente ADI ne 606-1/600, o Exmo. Sr. Governador do Estado do Paraná impugna $o$ inciso VII do art. 178 da Constituiçāo Estadual, que assim dispōem:

"Art. 178. O ensino será ministrado com base nos seguintes princípios:

VII - gestão democrática e colegiada das instituições de ensino pelo poder público estadual, adotando se o sistema eletivo, direto e secreto, na escolha dos dirigentes, na forma da lei."

8. Pelas mesmas razões deduzidas nos precedentes referidos, são inconstitucionais, no texto do inciso VIl do art. 178 da C.E. do Paraná, as expressões " adotando-se o sistema eletivo, direto e secreto, na escolha dos dirigentes, na forma da lei".

9. Penso que, no mais, o inciso VII não é de ser declarado inconstitucional, ou seja, no ponto em que estabelece, como princípio do 
ensino, no Paraná, a "gestão democrática e colegiada".

10. Isto posto, julgo PROCEDENTE, em parte. a Ação, para declarar a inconstitucionalidade, com eficácia "ex tunc". das expressões "adotando-se o sistema eletivo, direto e secreto, na escolha dos dirigentes, na forma da lei" contidas no inciso do art. 178 da Constituição do Estado do Paraná.

\section{VOTO}

O SENHOR MINISTRO MARCO AURÉLIO - Senhor Presidente, trata-se da gestāo democrática no ensino. Tenho convicção a respeito da matéria contrária ao que assentado pelo Plenário. Reporto-me ao voto proferido, transcrevendo-o em seu inteiro teor:

$\mathrm{Na}$ assentada em que teve inicio o julgamento, o Ministro Maurício Corrêa concluiu pela procedência do pedido formulado "para declarar a inconstitucionalidade do $\$$ I" do art. 213 da Constituição do Estado do Rio Grande do Sul e das Leis Estaduais n" 9.233, de 13 de fevereiro de 199I, e 9.263, de 05 de junho de 1991, por violação aos artigos 37. II e 84, XXV da Constituição Federal". Reportou-se a precedentes da Corte - Açāo Direta de Inconstitucionalidade n" 123, Relator Ministro Carlos Velloso, Açãoo Direta de Inconstitucionalidade n 490, Relator Ministro Octávio Gallotti, Ação Direta de Incons. titucionalidade $n^{2}$ 573, Relator Ministro Néri da Silveira e Ação Direta de Inconstitucionalidade n" 640, relatada pelo próprio Ministro Mauricio Corrêa. Em sintese o preceito constitucional versa sobre a gestão democrática do ensino puiblico, tendo o seguinte teor:

Art. 213. (...)

$\$ 1^{2}$ Os diretores das escolas públicas estaduais serão escolhidos, mediante eleição direta e uninominal, pela comunidade escolar, na forma da lei.

$\mathrm{Na}$ ocasiāo em que deferida a liminar, ressalvaram o comprometimento com o tema de fundo os Ministros Sepúlveda Pcrtence e Néri da Silveira.

No julgamento desta ação. acompanhou o nobre Relator o Ministro Nelson Jobim. sendo que se encontravam ausentes, justificadamente, os Ministros Ilmar Galvāo e Carlos Velloso.

Senhor Presidente, tenho convencimento diverso sobre a matéria tratada nestes autos - o sentido, em si, de viver-se em uma Federação, considerada a autonomia dos Estados federados - mitigada. é certo, pela Carta da República - isto sob o ângulo governamental e legislativo, não se chegando, obviamente ao campo da soberania. Em 3 de fevereiro de 1997, esta Corte julgou as Ações Diretas de Inconstitucionalidade $\mathrm{n}^{\circ} \mathrm{s} 123 \mathrm{e}$ 490, a envolverem preceito semelhante ao atacado neste processo - das Constituições de Santa Catarina e do Estado do Amazonas. Dois dias após, ou seja. em 5 de fevereiro de 1997, apreciou a Ação Direta de Inconstitucionalidade $n^{2}$ 640-MG, concluindo pelo conflito dos preceitos atacados com a Carta da República. Nos três processos, fiquei vencido, na companhia honrosa do então Presidente da Corte, Ministro Sepúlveda Pertence. Reitero o que tive oportunidade de consignar quando do julgamento da Ação Direta de Inconstitucionalidade $n^{2} 640$ :

$\mathrm{Na}$ inicial desta ação direta de inconstitucionalidade, argüi-se como infringidos os preceitos dos artigos 25,37 , inciso II, 84 , incisos II e XXV, da Constituição Federal. O primeiro deles cuida da organização dos Estados, com elaboração de constituição e leis de acordo os princípios da Carta Política da República; o segundo é célebre e diz da necessidade de a investidura de cargo ou emprego público ser precedida de aprovação prévia em concurso público de provas ou de provas e títulos. ressalvadas as nomeações para cargo em comissão, declarado em lei de livre nomeação e exoneração. Já os dois últimos dispositivos encerram a competência privativa do Presidente da República para exercer, com o auxílio dos Ministros de Estado, a direção superior da administração federal, provendo e extinguindo os cargos públicos federais, na forma da lei.

Em primeiro lugar, ressalto a ênfase dada pela Carta de 1988 à forma federativa da República. Atribuiu-se aos Estados autonomia governamental e competência legislativa. jun- 
gidas aos princípios estabelecidos na Constituição Federal. Quanto à competência para legislar sobre educação, no inciso XXIV do artigo 22 alude-se a diretrizes e bases da educaçāo nacional. notando-se. no inciso IX do artigo 24. a competência da Uniāo, dos Estados e do Distrito Federal para legislar concorrentemente sobre educação. cultura, ensino e desporto. Sob o ângulo do inciso II do artigo 37 da Carta Federal, verifica-se a remessa à lei, isso quanto às nomeações para cargo em comissāo, como são os de diretor e vice-diretor de escola pública. A premissa básica do preceito para que se tenha como livre a nomeação e a exoneração é justamente a previsāo em lei. Quanto ao artigo 84, incisos II e XXV, da Constituição Federal, nota-se que o provimento e extinção de cargos pelo Chefe do Poder Executivo há de ocorrer sempre na forma da lei. Pois bem, no caso dos autos, na própria Constituiçāo do Estado previu-se seleçāo competitiva interna para o exercício do cargo comissionado de Diretor e da função de Vice-Diretor de escola pública, homenageando, de maneira pedagógica, o mérito dos candidatos, a experiência profissional, a habilitação legal. a titulação, a aptidão para liderança, a capacidade de gerenciamento e a prestação de serviço no estabelecimento por dois anos, pelo menos. A partir do texto da Lei Maior local é que houve o encaminhamento de projeto de lei pelo Chefe do Executivo do Estado de Minas Gerais que, a seguir, veio a editar decreto. regulamentando-a (folhas 17 a 26).

Senhor Presidente, há de conferir-se algum sentido à Federação, caminhando-se para a tlexibilidade. de modo a reconhecer-se aos Estados federados certa independência normativa. No caso dos autos, năo tenho como infringido princípio básico da Carta da República. Ao contrário, a Constituiçāo do Estado de Minas Gerais homenageia o princípio federativo c, mais do que isso, a regra inserta no artigo 206, inciso VI, da Carta Federal. A forma de escolha dos diretores e vice-diretores das escolas públicas além de consubstanciar temperamento a atuação discricionária do chele do Poder Executivo, atendendo aos anseios da sociedade no que voltados para o critćrio de mérito, mostra-se em harmonia com o princípio segundo o qual o ensino será ministrado com base na gestão democrática. Aqui. sim. tem-se a fixaçāo, pela Carta da República. de princípio. como é dado notar no inciso VI do artigo 206 nela inserto. O preceito remete ao balizamento da citada gestāo democrática do ensino público constante de lei e o povo mineiro. mediante os respectivos representantes, fez opçāo, partindo para a disciplina da matéria conforme o inciso VIII do artigo 196. Não posso, na espécie, vislumbrar sequer arranhão ao Diploma Maior. Se de um lado é certo que compete ao Chefe do Poder Executivo o exercício da administraçāo superior, de outro, não menos correto é que o próprio artigo 84, inciso $X X V$, remete, quanto ao provimento dos cargos públicos, ao que estipulado na lei. No caso, a Constituição do Estado de Minas Gerais prevê a seleção competitiva. Há de tirar-se do Texto Constitucional Maior a máxima eficácia e efetividade possíveis e isso o faço ao assentar que se coaduna, a mais não poder, o preceito do citado inciso VI do artigo 206 à norma da Constituição do Estado de Minas Gerais. Assim, a par dos aspectos altamente positivos, no que a cláusula da Constituiçāo do Estado de Minas Gerais, bem como as insertas nas Cartas de outros Estados buscam colocar nos relevantes cargos as pessoas melhor capacitadas, afastando vícios anteriores no campo do apadrinhamento, tenho anda que exsurge a plena harmonia com a Constituição Federal. Digo mesmo que a regência da matéria, tal como ocorrida, serve ao que se contém na nossa Carta da Repúhlica. no que cuida da gestāo democrática do ensino público. Nāo vejo, preservadas as características próprias de uma Federação em que se mostra a feição descentralizadora, como concluir pela inconstitucionalidade do preceito.

Por tais razões, julgo improcedente o pedido formulado nesta açāo direta de inconstitucionalidade.

É o meu voto.

Peço vênia à nobre Ministro Relator para, assim. julgar improcedente o pedido formulado nesta açāo.

É o meu volo. (Ação Direta de Inconstitucionalidade $n^{2} 578-2 / R S$, relatada pelo Minis- 
tro Maurício Corrêa, perante o Pleno, e julgada na Sessão de 3 março de 1999)

Julgo improcedente o pedido formulado. É o meu voto.

\section{VOTO}

O SENHOR MINISTRO SEPÚLVEDA PERTENCE: Sr. Presidente, data venia do eminente Relator, acompanho o Sr. Ministro Marco Aurélio.

EXTRATO DE ATA

AÇÃO DIRETA DE INCONSTITUCIONALIDADE n 606-1

PROCED.: PARANÁ

RELATOR: MIN. SYDNEY SANCHES

REQTE.: GOVERNADOR DO ESTADO DO PARANÁ

ADV.: ROGERIO DISTEFANO E OUTRO

ADV.: JULIO CESAR RIBAS BOENG
REQDO.: ASSEMBLÉIA LEGISLATIVA DO ESTADO DO PARANÁ

Decisão: O Tribunal, por votação majoritária, julgou procedente, em parte, a ação direta e declarou a inconstilucionalidade da expressão " adotando-se sistema eletivo, direto e secreto, na escolha dos dirigentes, na forma da lei", contida no inciso VII do art. $178 \mathrm{da}$ Constituiçāo do Estado do Paraná, vencidos os Ministros Marco Aurélio e Sepúlveda Pertence. Votou o Presidente. Ausentes, justificadamente, os Ministros Celso de Mello (Presidente) e Carlos Velloso, e, neste julgamento, o Ministro Maurício Corrêa. Presidiu o julgamento o Ministro Moreira Alves. Plenário, 25.3.99.

Presidência do Senhor Ministro Moreira Alves. Presentes à sessāo os Senhores Ministros Néri da Silveira, Sydney Sanches, Octávio Gallotti, Sepúlveda Pertence, Marco Aurélio, Ilmar Galvāo, Maurício Corrêa e Nelson Jobim.

Procurador-Geral da República, Dr. Geraldo Brindeiro.

Luiz Tomimatsu

Coordenador 